\title{
APRESENTAÇÃO DO PROBLEMA DA EMPATIA NA QUINTA DAS MEDITAÇÕES CARTESIANAS E A CENTRALIDADE DO SOMA COMO RESULTADO DA REDUÇÃO ABSTRATIVA
}

\author{
PRESENTATION OF THE PROBLEM OF EMPATHY IN THE FIFTH OF \\ THE CARTESIAN MEDITATIONS AND THE CENTRALITY OF THE SOMA AS A \\ RESULT OF THE ABSTRACT REDUCTION
}

Thayla M. Gevehr ${ }^{1}$

RESUMO: Uma das objeções apresentadas à fenomenologia husserliana é a de que ela teria caído num solipsismo. Husserl, ao descobrir o ego transcendental, depois de realizar a redução fenomenológica, teria encerrado tudo neste ego e, com isso, não teria deixado "espaço" para o Outro. Para responder a esta objeção, é necessário que se investigue, a partir do terreno já conquistado pela fenomenologia, não só em que sentido o Outro pode ser para mim, mas, sobretudo, em que sentido o Outro pode ser comigo. O problema do sentido do aí do Outro para mim é denominado de "empatia". Consonante a este problema está o de uma "teoria da intersubjetividade", isto é, da teoria que pretende explicar como as vivências do ego próprio e as vivências do ego alheio poderiam referir-se a um mesmo mundo e como elas poderiam ser comprovadas, já que não se pode ter acesso direto às vivências do outro ego. No centro dessas questões ou como condução para tratar adequadamente dessas questões está a necessidade de que uma nova redução seja operada. Se é preciso saber como o Outro pode ser, para si mesmo, num mundo comigo, então é necessário que se saiba acertadamente o que pertence ao ego e o que pertence ao alheio. A redução abstrativa, cujo objetivo é separar justamente o que é próprio e o que não é próprio ao ego, é o que revelará o soma (corpo vivo) como aquilo que primeiro se encontra e como aquilo que permitirá avançar em direção à resolução do problema do aí-para-mim dos outros. Pensar os passos conceituais que revelam o Outro enquanto Outro consiste na tarefa deste trabalho.

Palavras-chave: Empatia. Intersubjetividade. Redução Abstrativa. Soma.

ABSTRACT: One of the objections presented to Husserlian phenomenology is that it would have fallen into a solipsism. Husserl, upon discovering the transcendental ego, after realizing the phenomenological reduction, would have shut everything down in this ego and, thereby, leave no "room" for the Other. To respond to this objection, it is necessary to investigate, from the terrain already conquered by phenomenology, not only in what sense the Other may be for me, but above all in what sense the Other can be with me. The problem with the sense of the there of the Other to me is termed "empathy." Consilient with that problem is the "theory of intersubjectivity", that is, the theory that intends to explain how the experiences of the ego itself and the experiences of the ego of others could refer to the same world and how they could be proven, since

\footnotetext{
1 Aluna regular do programa de doutorado em filosofia da UFG. Endereço eletrônico: gevehrthayla@gmail.com
} 
one can't have direct access to the experiences of another ego. At the center of these issues or the way to properly address these issues is the need for a further reduction to be operated. If it is necessary to know how Other can be for himself in a world with me, then it is necessary to know correctly what belongs to the ego and what belongs to others. The abstract reduction, whose objective is to precisely eparate what is particular and what is not particular to the ego, is what will reveal the soma (living body) as that which finds itself first and as that which will make it possible to advance towards the resolution of the problem of the from there-to-me of others. To think of the conceptual steps that reveal the Other as Other is the task of this work.

Keywords: Empathy, intersubjectivity, abstract reduction, soma

\section{APRESENTAÇÃO DO TEMA}

Na Quinta de suas Meditações Cartesianas, publicada em alemão em 1950, Edmund Husserl expõe o problema concernente à empatia como sendo o "problema do aí-para-mim dos outros", como sendo "tema de uma teoria transcendental da experiência do que me é alheio" (2013, p. 130. Grifo do autor). Incialmente, o que permite, por assim dizer, a exposição dos problemas e desenvolvimento da temática do Outro é o que se encontra como "substrato último" da redução fenomenológica, o ego transcendental. Se, tal como a fenomenologia transcendental mostrou, o "eu" e o mundo são inseparáveis (este permanece correlato daquele), se toda e qualquer vivência, toda e qualquer operação pela qual algo possa ser constituído como idêntico, todo e qualquer voltar-se para si depende do "eu", estaria a fenomenologia, como ciência, fadada a permanecer na cercania do mesmo (do ego)? Seria possível, a partir do ego transcendentalmente reduzido, responder pelo sentido do Outro enquanto Outro - isto é, não como um para mim, mas como aquele que é para si mesmo e comigo? Ou seria necessário, para desenvolver o tema da empatia, reavaliar o procedimento metodológico (o da redução) pelo qual o filósofo se valeu a fim de erigir sua fenomenologia?

De antemão, podemos dizer que não só é necessário que haja uma reavaliação metodológica, mas é justamente por um aprofundamento do método redutivo (MISSAGGIA, 2015, p. 212) que será possível alcançar o modo por que o Outro pode ser constituído. Justamente por isso, num primeiro momento, e antes de avançar na investigação pelo sentido do outro ego, Husserl mostra que há a exigência de delimitar aquilo que "me" é próprio. Só a partir dessa delimitação, o que pertence ao ego transcendentalmente reduzido se dará como que livre do que lhe é "estranho". 
Se, portanto, enquanto primeira coisa a se fazer, o ego for delimitado no que lhe é próprio, se for visto e articulado na sua consistência - não apenas de vivências, mas também de unidade de validade, que são concretamente inseparáveis dele -, então deverá, em conexão com isso, levantar-se a questão de saber como pode o meu ego, no interior da sua propriedade, constituir, sob o título "experiência alheia", precisamente algo alheio [...]? Essa problemática ganhará em compreensibilidade quando procedermos à caracterização da esfera de propriedade do ego, correspondente, quando executarmos explicitamente a epoché abstrativa que engendra essa esfera. (HUSSERL, 2013, pp. 132-133. Grifo do autor).

A epoché abstrativa, tendo por tarefa a delimitação do próprio, coloca entre parêntesis tudo o que é alheio e obtém como resultado o "aparecimento" do soma (corpo vivo) como pertencendo à esfera de propriedade. Por ele, o ego transcendental (enquanto mônada) apreende a si mesmo como unidade psicofísica. A apreensão que delimita o meu próprio e, consequentemente, o meu não próprio (o concernente ao outro ego), permite, a partir de um desenvolvimento progressivo, que os Outros sejam "tomados" como egos constituintes, como egos que também "partem" do seu próprio ego, ou seja, como possuindo estruturas constituintes semelhantes às minhas. Ainda que já tenhamos adiantado alguns passos, o fizemos para dizer que nossa tarefa consistirá em mostrar como o soma, resultado a que se chega pela redução abstrativa, tem um papel central para a apreensão e para o desenvolvimento progressivo da constituição do Outro enquanto Outro. Alcançando esse esclarecimento, acreditamos poder voltar às questões formuladas no início desse texto a fim de, na medida de nossa capacidade, respondê-las.

\section{A NECESSIDADE DA REDUÇÃO ABSTRATIVA}

De início, é importante notar que ao ego transcendental não está vedada a possibilidade de encontrar-se com o Outro. Por isso, não é como se a fenomenologia husserliana já, primordialmente, não constasse com a alteridade e que o tema do Outro fosse anexado, posteriormente, como mera preocupação, como se ele não fizesse parte do projeto que visou pensar a constituição do mundo primordial, a partir das reduções necessárias ${ }^{2}$, e mesmo a constituição do mundo objetivo (só possível, aliás, se aliado à

\footnotetext{
${ }^{2}$ Silveira aponta que há quatro tipos de reduções: a filosófica (suspensão das teorias científicas, das verdades inquestionadas), a eidética (suspensão das experiências sensíveis vindas do mundo e de seus objetos), a fenomenológica (suspensão de toda crença empírica ou psicológica, de tudo o que supõe a existência da fatualidade do mundo) e a transcendental (suspensão de todos os fenômenos vinculados ao eu psicológico e empírico). "Segundo Husserl, é justamente por meio destas operações que a fenomenologia 'ganha' o sentido do mundo que existe para o sujeito e 'ganha' também a possibilidade de
} 
"teoria da intersubjetividade"). Se a tematização da constituição de mundo como tendo sentido para e pelo ego transcendental depende da tematização da intencionalidade (pela qual sabemos que a consciência, essencialmente, é sempre em direção a alguma coisa) e de uma série de reduções, é essa mesma intencionalidade que revela como o Outro, ainda que não de maneira originária, por assim dizer, é intencionado. Na direção intencional da consciência, o ego alheio aparece como "algo" que ultrapassa aquilo que é constituído pelo ego monádico. Na intencionalidade dirigida para o alheio constitui-se, diz Husserl,

um novo sentido de ser que ultrapassa o ego monádico na sua propriedade mesma, e constitui-se um ego não como eu-mesmo, mas antes como espelhando-se no meu próprio eu, na minha mônada. Todavia, o segundo ego não está pura e simplesmente aí como ele mesmo dado em sentido próprio, mas é antes constituído como alterego, em que o ego que esta expressão "alter-ego" indica, como um dos seus momentos, sou eu-mesmo na minha propriedade. Segundo o seu sentido constituído, o outro remete para mim mesmo, o outro é reflexo de mim mesmo e, porém, não reflexo no sentido comum; o outro é análogo de mim mesmo e, de novo, porém, não o análogo em sentido comum. (HUSSERL, 2013, p. 132. Grifo do autor).

Por meio da intencionalidade, o Outro chega à consciência. O modo como chega, porém, não $o$ dá como um “eu mesmo", mas como reflexo do meu próprio eu. Isto quer dizer que esse ego espelhado não está aí enquanto Outro, ele mesmo, em sentido próprio; está constituído como "outro de mim”, remetido a mim, análogo a mim. É precisamente esse modo de encontro que torna urgente explicitar como o ego monádico pode constituir algo que escape ou ultrapasse aquilo que é por ele constituído, algo que lhe aparece como um análogo de si, mas um análogo "estranho", não “abarcado". Se o Outro é dado enquanto análogo a mim, enquanto algo que aparece, por um lado, como minha vivência, não quer dizer que o ego o possa acessar diretamente, tal como faz com aquilo que é constituído. Por isso mesmo há, na "constatação" dessa alteridade, um sentido que ultrapassa o ego constituinte. Essa ultrapassagem se dá justamente porque o alter-ego já aparece como precisamente Outro, isto é, não sendo "uma coisa" entre as outras ${ }^{3}$, mas sendo Outro em relação a mim (ou Outro em mim).

se referir às vivências de um modo universal, necessário e primordial. Portanto, 'ganha' a possibilidade de refletir sobre o sentido de Outro de modo originário ou absoluto”. (2010, p. 28-30).

3 “Como nós mesmos podemos perceber em nossas próprias vivências, o Outro se mostra como existente realmente, como objeto do mundo. Mas, não como coisa simplesmente, tal qual apreendemos as coisas em geral, como a árvore, a casa, a mesa etc.” (SILVEIRA, 2010, p. 76). 
Resta, todavia, explicitar o seu sentido e como o Outro pode ser "comigo" (um Outro com o ego e não só “no" ego).

Se o objetivo parece ser o de ultrapassar o sentido do Outro como outro-no-ego, é preciso aclarar, então, não só o modo como esse Outro é experienciado, mas o que é experienciado do Outro. Não se trata, pois, de permanecer nesse modo de encontro do ego alheio como "mera" vivência minha, se trata, como já dissemos, de explicitar o sentido do Outro enquanto Outro e isto só pode acontecer por meio da delimitação do que é próprio, efetuada pela redução abstrativa, e pelos procedimentos a serem explicitados posteriormente.

\subsection{REDUÇÃO ABSTRATIVA: A UNIDADE DO "CORPO VIVO" ENQUANTO ESTRUTURA PSICOFÍSICA}

Com a redução abstrativa, a fenomenologia coloca "entre parênteses" a distinção natural, mundana, entre eu e os "outros". Isso se dá porque a mera distinção fatual ou a mera consideração contingente de que eu fique só no mundo, caso um evento drástico tire qualquer outro ego do mundo, não delimita transcendentalmente aquilo que pertenceria ao ego como próprio. Em outras palavras, ficar sozinho, já a partir de uma distinção fatual entre o "eu” e os "não eu”, num mundo que pressupõe, de algum modo, o Outro não quer dizer ter desvelado o que é próprio ao ego a nível transcendental. A redução abstrativa revela uma natureza purificada de tudo o que é alheio ao ego, e, nessa natureza, encontra o soma, o corpo vivo,

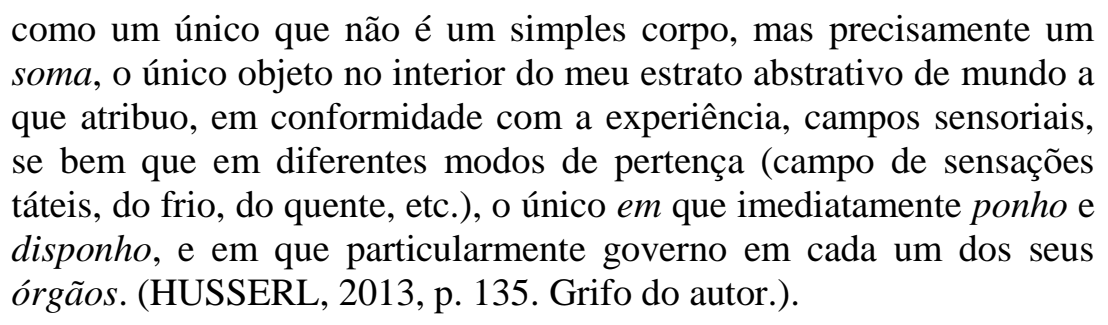

Esse soma que aparece na natureza é aquele por meio do qual é possível agir, fazer, sentir, etc. Tal corpo somático, que pertence à minha esfera de propriedade, é o modo por que o mundo pode ser explorado "por mim". Com isso, não está dito que esse corpo que tomo como meu é "para a consciência", mas que acontece como "consciência de ter corpo" (ALVES, 2008, p. 347. Grifo do autor). A essa consciência que vai para o 
mundo e se apercebe como "no mundo", Husserl denomina por Leib e coloca esse corpo que somos em diferença a um simples corpo (Körper).

Para entender melhor de que estamos tratando, é importante notar a diferença que há entre os vocábulos citados: “Körper diz respeito aos aspectos estritamente materiais, daquilo que ele tem em comum com todos os objetos do mundo, abstraindo, portanto, da sua conexão com a consciência". Leib, por sua vez, "é o corpo enquanto algo vivo, animado por uma alma e que envolve todos os aspectos psicológicos" (MISSAGGIA, 2015, p. 197).

Quando, abstrativamente, nos ocupamos do que é o corpo enquanto Leib, percebemos que a ele estão aplicadas leis e propriedade que ultrapassam, num certo sentido, a dos demais corpos (Körper). Embora o meu corpo próprio possa ser visto, tocado, ouvido, etc., porque físico (e isso o colocaria em relação de semelhança com os demais), ele, em diferença com um corpo qualquer, enquanto "recebe" uma impressão sensível, não apenas toca alguma coisa, mas sente o "tocar" do toque mesmo. Ao tocar ativamente qualquer parte do meu corpo (como o braço), sinto o toque e tenho a impressão tátil de que meu corpo foi tocado; sinto, nesse toque, que não apenas a minha mão, por exemplo, tocou o meu braço, mas que ela é tocada enquanto "toca". Nesse processo, se ainda considerarmos a visão, é possível "ver o ato" mesmo de tocar - vejo minha mão ir em direção ao braço, vejo-a entrar em contato com o mesmo e tenho, nisso, as impressões sensórias relativas a essa experiência sensível e perceptiva. Apesar de em relação à impressão tátil o "tocar-tocado" (a mão que toca o braço também se sentir tocada) funcionar em unidade de experiência, e nessa unidade minha visão desse movimento também acontecer já numa conexão, quando considero apenas a visão que acompanha a "experiência" do toque, por assim dizer, percebo que ela (a visão) não pode ser vista naturalmente. "Ver a visão" acompanhar a experiência tátil ou mesmo ver o meu próprio rosto requer algo que não é "natural" (só posso fazer isso com a ajuda de um espelho, por exemplo). Seja como for, é por meio do meu corpo que percebo, sinto, me dirijo em relação ao meu corpo e a qualquer outra coisa e por meio dele sou visto, tocado, ouvido, etc. 
A primordialidade do soma não está restrita apenas às sensações (passivas ou ativas) ou às percepções cinestésicas ${ }^{4}$ tornadas possíveis por ele, está, também, na orientação espaço-temporal por meio da qual é possível qualquer relação. Precisamente por ser o "ponto zero" (STEIN, 2004, p. 60) ou o centro no qual as coisas se organizam e ganham sentido (porque sentidas, percebidas), é possível dizer que algo está "ali” e "agora", ou seja, porque meu corpo vivo ocupa o "aqui" e "agora" centralizadores, tudo o que aparece nessa esfera espaço-temporal na qual ele está e abre só pode estar e ser em relação a ele. Nessa orientação mesma está aberta, ainda, a possibilidade de que meu corpo vivo, dotado de vontade e movimento próprio, movimente as coisas e a si mesmo, "alterando", com isso, a experiência que tem daquilo que lhe aparece. Se vejo algo por uma determinada perspectiva, por exemplo, posso vê-lo, se eu mudar ou se o mudar de posição, por outra perspectiva (a coisa continua a ser percebida como "a mesma coisa", só que por outro lado, graças a síntese que a consciência opera passivamente).

No corpo ou pelo corpo vivo está dada, assim, a centralidade, as possibilidades e os limites da percepção: o corpo próprio nunca ocupará uma posição que não seja o aqui dele e para ele, mas sempre poderá mudar de posição e ter as experiências relativas a essa mudança num "novo" aqui. No entanto, todas as experiências que lhe são atuais ou potenciais nunca poderão escapar dos limites de seu próprio corpo - nunca é possível ouvir, ver, sentir mais do que propriamente e naturalmente é, de fato, possível.

Em acréscimo ao que foi dito, é importante notar que toda e qualquer "experiência" realizada no corpo e por meio do corpo é acompanhada também de sentimentos. Ao pensarmos, por exemplo, na expressão "sinto frio" já está dada, em total conexão, tanto a sensação de frio que acomete o meu corpo quanto o incômodo da sensação, o sentimento desconfortável que a sensação de frio me causa. Tanto a “dimensão" corporal que permite a sensação, quanto a "dimensão" da alma ou ego, "onde" o sentimento, que não ocupa um lugar no "espaço", porque é de natureza psíquica, acontece, estão em unidade - quando sinto frio, sou eu, por meio do corpo que sou e dos sentimentos relativos à experiência de ser corpo, quem sente e se incomoda com o frio. (MISSAGGIA, 2015, 200). Por meio disso, podemos dizer que,

\footnotetext{
${ }^{4}$ As percepções cinestésicas "nos permitem alterar, antecipar e prever as possibilidades ainda não realizadas de percepções potenciais. É o caso, por exemplo, de sabermos que temos que nos aproximar para ler um aviso que está colado à parede da sala, ou, guiando-nos pela audição, encontrarmos a rua na qual alguém está tocando violino" (MISSAGGIA, 2015, p. 196).
} 
abstrativamente, podemos diferenciar aquilo que é relativo ao corpo e aquilo que é relativo à alma. Essa diferenciação, porém, não é indicação de que há uma dualidade entre corpo e alma, porque "a alma, como a unidade substancial que se manifesta nas vivências psíquicas singulares, está consolidada no corpo vivo, constituí com ele o indivíduo psicofísico" (STEIN, 2004, p. 67).

Diante dos resultados a que chegamos a partir da redução abstrativa, temos de pensar, agora, como o Outro pode ser dado enquanto Outro mediante a "centralidade" do corpo vivo, isto é, precisamos mostrar como a descoberta do corpo vivo pode ajudar, no fim das contas, a pensar e a resolver "os problemas" relativos ao outro ego.

\section{O CORPO VIVO E O OUTRO}

Por conta da realização da redução abstrativa, tudo aquilo que era alheio foi suspendido. Tal suspensão trouxe à tona o corpo vivo como circunscrito à esfera de propriedade. Esse corpo vivo, como "eu no mundo", abre a dimensão perceptiva na qual qualquer coisa pode aparecer, inclusive o corpo do Outro. A aparição do corpo alheio no campo perceptivo requer que questionemos, tal como afirma Iribarne, como poderíamos pensar o Outro enquanto Outro "se o único que tenho ante a mim é o seu corpo que percebo, de um modo semelhante ao que percebo a árvore ou a casa?” (1987, p. 60).

Logo após formular essa questão, a autora mesma reconhece que o corpo do Outro está separado qualitativamente de uma casa ou de uma árvore. Essa separação se dá porque o corpo alheio reflete o meu próprio corpo, diferente das coisas em geral. $\mathrm{O}$ corpo alheio, porém, não é reconhecido como o meu corpo vivo, não é factualmente o meu reflexo, mas "um corpo próprio, governado por uma psique, tal como tenho a experiência de governar o meu" (IRIBARNE, 1987, p. 60).

É justamente porque a redução abstrativa abre a possibilidade para que o corpo vivo seja descoberto e, nisso, o cenário no qual o corpo alheio pode ser percebido em analogia com o meu, que ele, o corpo do Outro, não pode ser visto como "mero" reflexo “de mim". Não trata, assim, de um Outro em mim; trata de um Outro do qual não tenho acesso às vivências, pois "se o que é próprio e natural do outro me estivesse disponível de um modo direto, então o outro seria apenas um momento da minha essência própria e, em conclusão, ele e eu seríamos o mesmo” (HUSSERL, 2013, p. 147). 
A descoberta do corpo alheio não encerra, pois, a explicação sobre a sua constituição. Com a descoberta dos corpos (do meu e do Outro que aparece para mim), estamos ganhando terreno no que se pode denominar de "experiência empática", isto é, a experiência do aí para mim dos Outros. Resta perguntar, então, a fim de prosseguir a análise, como se motiva, na esfera primordial do ego, a apresentação da esfera primordial de um Outro? (HUSSERL, 2013, p. 147). Só a clareza quanto à motivação a abertura, não causal, da apresentação do ego alheio - poderá esclarecer como o Outro pode ser tornado co-presente.

O conceito de apresentação, patente quando se pensa sobre a constituição da coisa, atua como aquilo que, na presença mesma de algo, também se tem, ainda que não sob foco, o que é co-presente. Considerando que uma das faces do cubo, por exemplo, apresenta ou torna co-presente a face que não está sob o foco de atenção, a face do cubo apenas apresentada pode tornar-se presente caso haja uma mudança de lugar, alterando o foco de perspectiva. Em diferença com o modo como as coisas são apresentadas, o Outro não se torna presente em suas vivências. Seu corpo vivo, seu estar "em carne e osso", mas não "em pessoa", revela que seu modo de ser e estar aí com "se trata de um tipo especial de presentificação, intercalado com uma presentação, com um verdadeiro dar-se em si mesmo" (IRIBARNE, 1987, p. 62). Expliquemos.

Quando o corpo do alheio entra no meu campo perceptivo, o campo que meu corpo próprio "alimenta", não o vejo como um simples corpo no qual uma alma é acrescentada depois de ter realizado a experiência desse corpo em seu aspecto físico. $\mathrm{O}$ corpo do Outro já aparece numa unidade. A partir da percepção de mim mesmo como corpo, do saber que sou corpo, ocorre "uma transposição aperceptiva a partir do meu soma" que torna possível que o corpo alheio fique ligado ao meu, seja apreendido como análogo ao meu: "é desde agora claro que só uma semelhança, no interior da minha esfera primordial, ligando aquele corpo ali com o meu próprio corpo, pode fornecer o fundamento motivacional para a apreensão analogizante do primeiro como um outro soma" (HUSSERL, 2013, p. 149. Grifo do autor).

\footnotetext{
5 "O outro se apresenta diante de nós em sua plenitude concreta, em carne e osso. Mas não se manifesta "em pessoa", nem jamais será possível que o faça. Só assim o eu alheio é realmente outro eu. Se eu pudesse percebê-lo diretamente, ele se converteria eo ipso em mim mesmo, se identificaria comigo, e seu mundo passaria a ser o meu. A analogia se converteria em identidade" (XIRAU, 2015, p. 232).
} 
É evidente que não experiencio o corpo do Outro como experiencio o meu. Mas no modo mesmo como me experiencio, me autopercebo, permite que, em mim, na minha esfera primordial, apareça, por meio da denominada "transposição aperceptiva", o que não me é próprio - o corpo alheio como corpo habitado e presidido por um "eu". Quando o outro corpo vivo aparece, a apercepção assimiladora reconhece que este não é o meu corpo, mas o corpo alheio, com modos de agir e de ser análogos aos meus. “Assim como o meu ser espiritual está implícito em meu próprio organismo, o organismo análogo que se revela diante de mim pressupõe e incorpora um eu igual ao meu, que se contrapõe a mim como outro" (XIRAU, 2015, p. 231).

Com isso, está indiretamente explicada a apresentação e o que está atuando ao fundo, por assim dizer, da apreensão analogizante: o emparelhamento. Tal conceito, desenvolvido por Husserl no parágrafo 51, de suas Meditações, é indicado como sendo a síntese passiva de associação. No campo perceptivo primordial, o ego, em plena posse do corpo que é, prestando ou não atenção a si, é o fundamento no qual a associação e apercepção do alter-ego podem acontecer. Aquilo que vivencio na minha esfera própria, aquilo que pertence a mim, é diferente daquilo que se mostra como sendo relativo ao alheio. O que é relativo ao alheio é de nível superior porque nunca o posso acessar diretamente, mas dele só tenho uma apresentação.

Por meio do que me é presentado - o corpo do Outro -, tenho como co-presente aquilo que só me é apresentado como não acessível - o ego alheio, as suas vivências. Quando assimilo, a um só golpe, o Outro (em sua presentação e apresentação) como sendo um ego semelhante ao meu, já o tenho em unidade com seu corpo. Essa unidade não depende de uma tematização explícita para acontecer, como destacamos anteriormente. $\mathrm{O}$ emparelhamento, assim, é justamente aquilo que, na percepção de um corpo vivo, torna possível que seja apresentado (não de modo direto) a mim uma outra vida de consciência, uma vida apreendida por analogia com a minha, uma vida que tem um mundo próprio tal como tenho um mundo próprio, uma vida na qual eu apareço como Outro.

A experiência do outro, portanto, envolve não apenas a ideia geral de um outro corpo semelhante ao meu, mas também sua conexão com um "outro eu", com um ego semelhante a mim, igualmente dotado de uma "alma". O outro eu, portanto, não é mera alteridade abstrata, mas é tomado de maneira genuína na experiência empática. [...] o outro ego é concebido como um sujeito que, tal como o ego próprio, vivencia 
um mundo primordial no interior de sua consciência enquanto fonte primária de todo o sentido. (MISSAGGIA, 2015, p. 219).

Se, como vimos, meu corpo próprio abre o campo perceptivo no qual o Outro pode aparecer, esse campo perceptivo aberto só "confirma" a experiência do Outro enquanto Outro se houver, ali, uma transferência aperceptiva, isto é, se o corpo do alheio já aparecer como semelhante ao meu, como sendo presidido por um ego. Nessa transferência aperceptiva, ou nessa doação de sentido ao Outro a partir da minha autoapercepção, não ignoro que há, no alheio, algo que me é presentado - seu corpo próprio - e algo que me é apresentado - seu ego, como possuidor de vivências próprias. Mesmo que seja possível diferenciar o que é presente e o que é apresentado, trata de uma mesma unidade de sentido, trata do alheio, do diferente de mim, mas não um diferente circunstancial, é um diferente concebido por analogia: é um outro ego, tomado como Outro a partir da minha esfera de propriedade, possuindo, entretanto, um sentido que a ultrapassa. Ultrapassa porque não é um idêntico, mas de associação (a síntese passiva do emparelhamento). Essa associação, ainda, não deve ser tomada como algo que se dá logicamente, ou como deduzida a partir da reflexão. A associação, o emparelhamento, é já o colocar em "parelha”, em analogia (ou numa relação apreendida como analógica), o outro ego como semelhante a mim, como ligado a mim, como sendo o Outro - um ego, um sujeito enquanto outro ego transcendental, enquanto mônada.

Pode ser depreendido, então, que do mesmo modo que sou a fonte de doação de sentido e nessa doação há algo do Outro que me escapa, o que precisamente o torna Outro (seu ego, suas vivências, seu mundo primordial), também apareço para ele como algo que lhe escapa. Mas esse caminho inverso só pode ter o meu próprio caminho (meu próprio ego) como referência. Ambos, em suas estruturas constituintes de mundo, têm um mundo próprio, são egos um para o outro. Todavia, como poderíamos saber que os dois mundos primordiais estão em relação e tratam de um mesmo mundo? O que garante identidade a esses "mundos distintos"? Como posso saber que o mundo constituído pelo Outro é igual ao mundo constituído para mim, se não tenho acesso direto às suas vivências?

\section{MUNDO PRIMORDIAL E MUNDO OBJETIVO}


Quando Husserl, no parágrafo 43, afirma que o problema da empatia envolve o problema do aí-para-mim dos outros, afirma, logo em seguida, que o desenvolvimento de tal problemática levaria a fundamentação de uma "teoria transcendental do mundo objetivo" (2013, p. 130. Grifo do autor). Isto se dá porque o mundo no qual meu corpo vivo se move e meu eu psicológico vive e reage está intimamente ligado à natureza na qual o corpo do alheio (que também se move), governado pelo seu eu (que também vive e reage) estão. Mesmo que eu não possa acessar diretamente o Outro, transcendentalmente, por uma série de processos, é possível reconhecê-lo como análogo a mim. Essa analogia permite que o alheio seja visto como dotado das mesmas possibilidades que eu - como livre para se movimentar, como aquele que tem sentimentos, sensações, perspectivas, como aquele é constituidor de mundo. O mundo no qual eu estou e o mundo no qual o alheio está são o mesmo e o que garante essa "identidade é a possibilidade para mim e para ele, de mudar de lugar e de considerar as coisas de qualquer ponto de vista" (XIRAU, 2015, 236) confirmando-as.

$\mathrm{Se}$, tal como vimos, ao corpo próprio pertence um "aqui" centralizador e tudo o que se mostra para ele ocupa um "ali” ou um "lá", é justamente pela capacidade de movimentação, percepção e da consciência constitutiva que é possível intencionar não só os corpos em geral e o corpo do Outro, mas, também, a dimensão espacial vinculada ao corpo próprio. Pela "capacidade" de movimentação, por poder ocupar qualquer lugar no espaço, meu corpo próprio pode converter o que aparecia como "ali" ou "lá" num “aqui”. Com a mudança de lugar, altera-se a perspectiva que eu tinha da coisa, embora a coisa permaneça a mesma, só que observada ou perspectivada por um novo ângulo. $\mathrm{O}$ Outro, nisso, percebido como dotado de um corpo semelhante ao meu, de uma vida intencional semelhante a minha, ou seja, como possuidor das mesmas estruturas constituintes que eu, quando aparece a mim como estando ali, não aparece, apenas, como ocupando um mero lugar no espaço, mas como aquele que, semelhante a mim, ocupa seu "aqui" centralizador e tem as mesmas percepções que eu poderia ter se estivesse em seu lugar. Tenho, nisso, do meu lugar (do meu aqui), as mesmas perspectivas que o Outro teria caso estive onde estou (se convertesse o meu aqui, que lhe aparece como ali, no seu próprio aqui).

Justamente porque o corpo vivo é dado de tal maneira que aparece já em conexão com o mundo, com o centro espaço-temporal aberto a ele, toda e qualquer 
coisa está nesse "centro" organizador. O outro ego, análogo a mim, possuidor de corpo vivo semelhante ao meu, também está conectado com o mundo, interagindo com o mundo do mesmo modo que eu.

A pressuposição de que o Outro tem as mesmas perspectivas e pode ter as mesmas percepções que eu teria, caso eu estive onde ele está, só é possível porque o concebo como análogo a $\mathrm{mim}^{6}$. De fato, há que se admitir que as impressões que o Outro tem são, em alguma medida, diferentes das minhas, isto se deve porque a condição de seu corpo lhe causa uma determinada orientação e ele tem os limites relativos ao corpo - ele ocupa um aqui e nesse aqui meu eu, para ele, ocupa um ali; no seu aqui, as orientações ou perspectivas que ele tem lhe são próprias, o modo como ele experiencia lhe é também próprio. Isso não quer dizer que aquilo que constituímos ou concebemos não seja já proveniente de um e mesmo mundo. Ao contrário, saber que o Outro é tal como sou mostra não apenas "a possibilidade do enriquecimento da própria imagem do mundo através dos outros", mas "a relevância da empatia para a experiência do mundo externo real". (STEIN, 2004, p. 81).

Saber que o Outro é um corpo vivo que age e interage com o mundo não é um mero saber. Não trata de um agir ou interagir com uma mera realidade na qual eu não estou, como se fosse uma realidade outra. É claro que ao ego do outro estão reservadas vivências que são suas da mesma maneira que ao meu ego estão reservadas vivências que são minhas. Essas vivências, no entanto, se confluem. Porque o outro ego, desde a sua perspectiva e desde a possibilidade de mudança, semelhante a mim, tem aberta a realidade como o que se dá num fluxo de experiências atuais e possíveis, ele se relaciona comigo (e eu com ele) e com a realidade na qual estamos e compartilhamos. Com isso, a diversidade de perspectivas possíveis, devido à mudança de lugar e de orientação, não é um argumento que invalidaria a identidade do mundo ou o saber que estamos no mesmo mundo. Isso porque, como já afirmamos, posso mudar sempre de lugar e ver o que o Outro vê (o contrário também é verdadeiro). "Posso situar-me na perspectiva do próximo e ele pode adotar a minha; nós a nomeamos com significações idênticas, inteligíveis para todos, e em princípio podemos comprovar essas menções através de uma plenitude intuitiva, acessível a todos” (XIRAU, 2015, 239).

\footnotetext{
6 "Ela é a mesma natureza, apenas que no modo de aparição como se eu atuasse ali, no lugar do corpo somático alheio". (HUSSERL, 2013, p. 161. Grifo do autor).
} 
Já que eu e o Outro temos vivências próprias, mas que se referem a um mundo partilhado, a possibilidade da confirmação ou correção daquilo com que temos experiência é sempre vigente. No momento em que eu identifico aquilo que constituo em minha esfera própria com aquilo que é constituído na esfera própria do Outro, a partir de uma comunicabilidade essencial, o mundo objetivo ou aquilo que é objetivado tem uma validação intersubjetiva, começa a ganhar "corpo" e "realidade".

Só posso validar o mundo partilhado, ou saber que trata do mesmo mundo, por assim dizer, se houver, antes, a constituição de um mundo primordial no e a partir do meu ego. Mesmo que meu mundo primordial esteja separado do mundo primordial alheio, que eu e ele estejamos realmente separados mundanamente, e sejamos um para o outro apenas apresentados, não significa que a confirmação ou negação de nossas experiências seja impossibilitada ou permaneça infundada. Eu e o Outro estamos, por conta da semelhança constituinte e por estar, por nossos corpos vivos, conectados com o mundo, ligados. Essa ligação permite a comunicação do que é vivenciado por e pela nossa consciência e permite também a correção de nossas experiências: "da mesma maneira que as vivências próprias do ego são constantemente corrigidas e entre si concatenadas de modo a formar um conjunto coeso e dotado de sentido, também as experiências partilhadas com os demais sujeitos são unificadas coerentemente". Esse procedimento está envolto na possibilidade constante "de correção intersubjetiva por meio da comunicabilidade essencial partilhada pelos sujeitos e garantida pelo mundo comum". (MISSAGGIA, 2015, p. 223).

Diante disso, sabemos que o mundo primordial é o correlato da consciência "particular", mas o mundo objetivo só pode ser correlato da intersubjetividade, isto é, dos mundos primordiais referenciados, partilhados. Embora essa esfera intersubjetiva dependa da primordialidade, ela só tem sentido porque os egos já estão abertos uns aos outros para conviverem, dialogarem e constituírem uma comunidade ${ }^{7}$. A comunidade constituída, por sua vez, não é determinada, limitada, mas é aberta para que haja o encontro de outros egos como sempre referidos a mais outros no campo do efetivo e do possível. Porque os sujeitos constituintes do mundo primordial são o "desde onde" é

\footnotetext{
${ }^{7}$ A essa comunidade aberta, Husserl chama de "intersubjetividade transcendental" (HUSSERL, 2013, p. 168).
} 
possível pensar o Outro e o mundo objetivo, eles são abertos, por via de consequência, para a comunidade, para uma realidade partilhada e comunicada.

\section{CONSIDERAÇÕES FINAIS}

Vimos, aqui, que, num primeiro momento, o Outro é experimentado apenas como aquele que aparece, de um modo estranho, em mim. A intenção que o constitui revela que no alter-ego, o ego que permanece ali é o meu mesmo e, por permanecer, constitui para si um outro como reflexo de si, um análogo, mas não em sentido comum. O problema ou limite dessa intenção, porque ainda não havia sido depurado o campo em que o Outro poderia aparecer em sentido próprio, é que ela ainda não permite que a descrição do Outro apreendido como "outro eu” seja feita. Tem-se, ali, apenas um Outro em mim e não um Outro comigo (como um para si). A pressuposição de que o outro ego possa ser comigo não quer dizer que ele deixe de ser visto em semelhança ou em analogia a mim, pelo menos na descrição de seu sentido. É justamente porque parte-se do ego (conquistado pela redução transcendental) que o sentido de ser desse Outro precisa ser posto em questão: ele (o Outro) não pode mais ser uma simples projeção de mim mesmo, mas aquele que, em seu ser outro ego, é interpretado e visto, em todos os seus atos, em seu ser e estar no mundo, em analogia a mim. Como vimos, é isso o que Husserl pretende quando, por empatia, define que o que está em jogo não é só o problema de apreender o outro como outro eu, mas também o Outro como aquele que, semelhante a mim, está "no mundo" - e se está no mundo está "comigo" (tem ou pode ter uma experiência do mundo e de mim como outro ego).

A fim de resolver os problemas aqui apresentados, Husserl empreendeu uma nova redução no "interior" daquela que revelou o ego monádico. Essa nova redução, a abstrativa, pretendeu, assim como foi dito, suspender tudo o que era tido como referido ao alheio pelo ego, pretendeu tornar clara a distinção entre o que me pertence e o que pertence ao Outro. Nessa suspensão, o corpo vivo, presidido por um ego, foi conquistado. Tal conquista permitiu que o campo em que o Outro poderia aparecer, no que há em si de acessível, fosse dado - o campo perceptivo, no qual, por uma transposição apercepetiva, reconheço o corpo vivo alheio como um corpo semelhante (análogo) ao meu. A analogia aqui referida ou a apreensão pela qual concebo o Outro como análogo a mim é "desempenhada", se assim pudermos dizer, por uma síntese 
passiva a que Husserl denominou de emparelhamento. Este, ao reenviar a simples percepção do corpo vivo, reconhecido como tal pela transposição aperceptiva, para um âmbito em que esse corpo é concebido como "lugar" de apresentação (ALVES, 2008, p.348), isto é, como aquele que comporta um "eu”, conquista, com isso, o outro sujeito como aquele que, semelhante a mim, tem experiência de mim e do mundo que lhe circunda - a partir do campo perceptivo aberto pelo seu corpo (pelo seu ser corpo) e dos atos constituintes relativos ao ego.

A apreensão do Outro enquanto Outro começa pela apreensão de seu corpo como estando "no mundo", um corpo que se mostra como semelhante ao meu, como diferente dos simples corpos. É claro que essa tomada analógica não acontece sem uma espécie de verificação. É só porque o corpo do Outro, como corpo presidido por um ego, como aquele que está no mundo e é constituinte de mundo, em seus atos, é verificado pelo ego que medita como aquele que tem sensações, sentimentos, perspectivações (todos os atos constitutivos), movimentos semelhantes ao seu, que se tem a possibilidade de não tomar o corpo do Outro como mero corpo ou como um autômato, por exemplo.

Mesmo que, a título de explicação, diferenciemos o corpo e o ego não significa que a apreensão se dê em partes. O Outro já é apreendido como outro ego, como estando no mundo como unidade psicofísica. E, ainda que eu não tenha acesso às suas vivências, sei que ele é outro ego porque de modo análogo ao meu ele é e se comporta no mundo. Nossas constituições de mundo, ou nossas vivências de mundo, se coincidem e dizem respeito a um só e mesmo mundo - somos abertos, como sujeitos, a outros sujeitos, nos comunicamos, usamos as mesmas significações para os mesmo objetos de referência, etc. Somos de tal modo que não nos está vedada a possibilidade de aprender com outros povos a sua linguagem, o seu modo de ser e estar em determinado contexto e mesmo de referenciar os objetos - somos e estamos sempre, efetiva e potencialmente, abertos aos outros egos e aos seus modos de comportamento.

Por tudo isso, é possível saber não só como o sentido do Outro é esclarecido, mas como o Outro se dá enquanto Outro comigo, agindo e interagindo no mesmo mundo. Esse nosso agir e interagir no mundo podem ser verificados, já que estamos e somos imersos nas mesmas possibilidades de ser, estar e nos comunicar (por intermédio da interpretação dos comportamentos uns dos outros, pelo diálogo, etc) sobre nós, com 
os outros e sobre o mundo com os objetos que lhe compete. Esse saber mostra, no fim das contas, que a conquista do ego transcendental como o que há de apodítico não impede que o Outro seja pensado, não impede que seu sentido seja trazido à tona e não impede que o mundo objetivo - o mundo que não depende de apenas "um" ego, mas de uma comunidade de egos - seja esclarecido em seu sentido.

Com a descrição do sentido do Outro, resolve-se, por via de consequência, o problema do solipsismo outrora levantado - o de saber se a fenomenologia husserliana não estaria restrita a permanecer na cercania do eu transcendental. Com a possibilidade da depuração do campo em que o Outro pode ser dito como um ego transcendental, Husserl acabou por esclarecer o sentido em que eu e o Outro podemos ser e estar num mundo partilhado, num mundo que depende de que eu o constitua em sentido próprio, mas que, nessa dependência, não está "fechado" a comunicação, a interação, porque eu e o outro ego já sempre estamos em harmonia, já somos num mesmo mundo e já partilhamos dele.

\section{BIBLIOGRAFIA}

ALVES, Pedro. "Empatia e ser-para-outrem: Husserl e Sartre perante o problema da intersubjetividade”. Em Estudos e pesquisa em psicologia. UERJ, RJ, Ano 8. N. 2, $1^{\circ}$ semestre de 2008, pp. 334-352.

HUSSERL, Edmund. Meditações Cartesianas e Conferências de Paris. Tradução de Pedro Alves. $1^{a}$ ed. Rio de Janeiro: Forense, 2013.

IRIBARNE, Julia. La Intersubjetividad em Husserl: bosquejo de uma teoria. Volume 1. Buenos Aires: Ediciones Carlos Lohlé, 1987.

MISSAGGIA, Juliana. Redução, intencionalidade, mundo: a fenomenologia husserliana como superação da oposição entre realismo e idealismo. Porto Alegre: PUCRS, 2015. (tese de doutorado).

SILVEIRA, Alice. O sentido transcendental do outro na fenomenologia husserliana. Goiânia: UFG, 2010. (dissertação de mestrado).

STEIN, Edith. Sobre el Problema de la Empatia. Madri: Trotta, 2004.

XIRAU, Joaquim. Introdução a Husserl. Tradução de Vera Ribeiro. $1^{\mathrm{a}}$ ed. Rio de Janeiro: Contraponto, 2015. 